\title{
Comunicação
}

[Communication]

\section{Anticorpos contra vírus do grupo da língua azul em caprinos e ovinos do sertão de Pernambuco e inferências sobre sua epidemiologia em regiões semiáridas}

\author{
[Antibodies against bluetongue-virus group in goats and sheep from Pernambuco state and inferences on \\ bluetongue epidemiology under tropical conditions]
}

\author{
I.O. Mota $^{1}$, R.S. Castro $^{2}$, S.P. Alencar ${ }^{2 *}$, Z.I.P. Lobato ${ }^{3}$, C.D.F. Lima Filho ${ }^{4}$, \\ T.L. Araújo Silval ${ }^{1}$ A.C.T. Dutra ${ }^{4}$, S.A. Nascimento ${ }^{2}$ \\ ${ }^{1}$ Aluna de pós-graduação - Universidade Federal Rural de Pernambuco (UFRPE) - Recife, PE \\ ${ }^{2}$ Universidade Federal Rural de Pernambuco -UFRPE \\ Rua Dom Manoel de Medeiros s/n, Dois Irmãos \\ 52171-900 - Recife, PE \\ ${ }^{3}$ Escola de Veterinária - Universidade Federal de Minas Gerais - UFMG - Belo Horizonte, MG \\ ${ }^{4}$ Programa de Melhoria da Sanidade Caprina e Ovina de Pernambuco - UFRPE - Recife, PE
}

Língua azul (LA) é uma arbovirose transmitida por insetos hematófagos do gênero Culicoides a ruminantes domésticos e silvestres. Sua distribuição geográfica está condicionada a uma complexa interação entre o vírus, o vetor e o hospedeiro, fortemente influenciada por fatores ambientais, que afetam a capacidade vetorial, a dinâmica populacional dos Culicoides e sua interação com os vertebrados no tempo e no espaço. Onde as temperaturas são adequadas, a precipitação pluviométrica passa a ser o principal fator ambiental relacionado à abundância do vetor, provavelmente pelo aumento dos sítios de reprodução (Mellor et al., 2000).

O Brasil reportou-se oficialmente à Organização Mundial de Saúde Animal (OIE) relatando evidências sorológicas da ocorrência da LA em 1978. A partir daí, os vários levantamentos sorológicos realizados, inclusive no semiárido, demonstraram que o vírus da LA (VLA) está se difundindo pelo país (Costa et al., 2006; Alves et al., 2009; Tomich et al., 2009), onde várias espécies de Culicoides foram registradas em todas as regiões geográficas, inclusive no estado de Pernambuco, porém os trabalhos que estudaram essa temática em condições tropicais semiáridas, onde a LA é endêmica, ainda são escassos.
Considerando-se a presença do gênero Culicoides no semiárido brasileiro, a relação positiva existente entre estes vetores e o VLA, os registros recentes de surtos de LA no Brasil, a elevada ocorrência de defeitos congênitos em caprinos e ovinos no semiárido brasileiro e a suspeita de que essas malformações possam ter como causa a infecção pelo VLA, objetivou-se estimar a prevalência de anticorpos contra o VLA em caprinos e ovinos no sertão do estado de Pernambuco e avaliar, preliminarmente, as condições climáticas para a manutenção de Culicoides em ambientes tropicais semiáridos.

O sertão de Pernambuco corresponde a dois terços do território estadual, tem clima tropical semiárido e precipitação pluviométrica acumulada anual abaixo de $800 \mathrm{~mm}$. Contribui com $87 \%$ do rebanho estadual de caprinos e $79 \%$ de ovinos. Está dividido em duas mesorregiões Sertão Pernambucano e São Francisco Pernambucano -, onde o estudo foi realizado, contemplando os municípios de Sertânia, Serra Talhada, Carnaíba, Tuparetama, Iguaraci, Araripina, Ouricuri, Parnamirim, Exu, Petrolina, Orocó, Jatobá e Floresta. Nesta região, o sistema de produção de pequenos ruminantes consorcia a criação de caprinos e ovinos com bovinos em propriedades que possuem instalações simples,

Recebido em 23 de maio de 2010

Aceito em 17 de agosto de 2011

* Autor para correspondência (corresponding author)

E-mail: spalencar@bol.com.br 
utilizadas para produção de carne e, excepcionalmente, leite, e cujo manejo sanitário não inclui vacinação que previna contra o VLA.

A prevalência de animais soropositivos para LA foi estimada com base em um estudo onde o número mínimo de amostras $(\mathrm{n}=384)$ foi calculado utilizando-se o programa Epi-Info, versão 3.5.1 (Dean et al., 2001), considerando: p - prevalência esperada de $50 \%, \mathrm{z}$ - fator determinante do grau de confiança de $95 \%$ e d erro amostral de $5 \%$ de p. Foram colhidas amostras de sete matrizes, um reprodutor e dois animais jovens aleatoriamente selecionados em cada rebanho, sendo um total de 41 de caprinos e 40 de ovinos, escolhidos por conveniência. As frequências foram comparadas por meio do teste qui-quadrado ou do teste exato de Fisher, considerando $95 \%$ como grau de confiança.

Para detecção de anticorpos precipitantes contra o VLA foi utilizada a técnica de imunodifusão em gel de ágar (IDGA), segundo Pearson e Jochim (1979), utilizando, como antígeno, concentrado do sobrenadante de culturas de células VERO infectadas com o sorotipo 4 do VLA (Costa, 2000).

Para inferir sobre as condições ambientais foram obtidas informações sobre precipitação pluviométrica e temperaturas máxima e mínima (LAMEPE, 2008).

Os resultados mostraram prevalência de rebanhos soropositivos de $24,4 \%$ e $27,5 \%$ para os caprinos e ovinos, respectivamente. Isto indica que há circulação de um vírus deste grupo na região, pois o antígeno empregado é grupoespecífico e não permite a diferenciação entre anticorpos induzidos pela infecção causada pelo vírus da doença hemorrágica epizoótica (VEHD) e entre os diferentes sorotipos do VLA.

As prevalências de animais soropositivos foram baixas nas duas mesorregiões estudadas, com $3,9 \%$ para caprinos e $4,3 \%$ para ovinos, sem que fossem observadas diferenças significativas entre as espécies. As prevalências observadas são próximas às relatadas em ovinos no estado da Paraíba (Alves et al., 2009) e em ovinos no Rio Grande do Sul (Costa et al., 2006). Prevalências mais elevadas foram observadas em outros estados de clima tropical semiárido, como Ceará, com $30,2 \%$ de soropositividade em caprinos
(Silva, 2002), e de clima tropical úmido, como Minas Gerais, 41,2\% em caprinos e 58,6\% em ovinos (Laender, 2002, onde as temperaturas e a precipitação pluviométrica são adequadas para a contínua multiplicação dos Culicoides.

Estas estimativas da prevalência devem ser interpretadas com cautela, quando se pretende inferir sobre a realidade da infecção pelo grupo do VLA na população, pois se sabe que é possível haver superestimativa de resultados positivos quando a prevalência real é baixa, dependendo da sensibilidade do teste diagnóstico utilizado. Neste trabalho, visando minimizar essa possibilidade, utilizou-se um teste que apresenta alta especificidade para o grupo do VLA e alto valor preditivo positivo, diminuindo o "peso" dos resultados falso-positivos no cálculo da prevalência estimada.

Divergências entre as prevalências estimadas por amostragem probabilística na mesma região e espécie, porém em tempos diferentes, como $5,9 \%$ e $41,2 \%$ em Minas Gerais, e entre regiões semiáridas que apresentam condições geográficas similares, como as dos sertões cearense, 30,2\% (Silva, 2002), e paraibano, 0,0\% e 8,4\% (Alves et al., 2009), sugerem que há variação temporal na exposição à infecção pelo VLA nessas áreas, ou mesmo que o VLA pode ter surgimentos periódicos, com anos de intervalo, o que pode acarretar, em um estudo pontual, que as amostras sinalizem para um período de baixa circulação vírica.

No caso particular do semiárido, onde a precipitação pluviométrica deve ser o principal fator responsável pela sazonalidade dos Culicoides, mudanças climáticas cíclicas, como os intensos episódios El Nino/Oscilação Sul (ENOS), caracterizados por períodos secos intensos seguidos por precipitações pluviométricas acima do normal, podem resultar em alterações do equilíbrio no ecossistema e, ao final do seu efeito, quando há aumento da precipitação pluviométrica, promover intensa multiplicação de Culicoides competentes, resultando em intensa circulação viral.

Embora não existam estudos sobre Culicoides no semiárido de Pernambuco, há relatos da presença de várias espécies $-C$. insignis, $C$. recifei, $C$. leopoldoi, C. brasilianum, C. debilipalpis, $C$. flavivenula, C. foxi, C. guyanensis, C. insignis, 
C. leopoldoi, C. maruim e C. uniradialis (Forattini, 1957) - descritas no litoral do estado, a cerca de $600 \mathrm{~km}$ do sertão. Dentre esses, o $C$. insignis tem sido incriminado como importante vetor para o VLA em outras regiões (Melo et al., 2000); assim, é provável que as espécies citadas também possam ser encontradas no sertão, pois a dispersão de Culicoides pode ocorrer a distâncias superiores a 700km (Mellor et al., 2000) e, nesse caso, somada à ajuda dos ventos, que, em Pernambuco, deslocam-se do litoral para o sertão.

A observação das principais variáveis climáticas, que interferem na dinâmica da população e competência de Culicoides nos municípios estudados, mostrou que a temperatura sofreu pequenas variações (mínimas de $18,2^{\circ} \mathrm{C}$ a $21,3^{\circ} \mathrm{C}$ e máximas de $29,9^{\circ} \mathrm{C}$ a $34,5^{\circ} \mathrm{C}$ ) nos diferentes meses do ano, e que a precipitação pluviométrica variou significativamente, de forma a definir claramente um período chuvoso $(44 \mathrm{~mm}$ a $613 \mathrm{~mm})$ e outro seco $(7 \mathrm{~mm}$ a $28 \mathrm{~mm})$. Dessa forma, embora não tenham sido realizados estudos entomológicos, é possível inferir que a precipitação pluviométrica seja o principal fator responsável pela dinâmica da população dos vetores nesta região (Mellor et al., 2000).

Apesar da ocorrência de períodos secos no semiárido, os quais poderiam limitar a reprodução dos Culicoides, existem microclimas no sertão que apresentam reservas importantes de água e ambientes mais úmidos, os quais serviriam como sítios para reprodução e manutenção de insetos adultos durante todo o ano, mantendo-os para repovoamento das áreas mais secas por dispersão por meio dos ventos. Dentre os microambientes propícios para a reprodução dos Culicoides, há de se considerar ambientes ricos em matéria orgânica, sobretudo aqueles próximos às instalações dos animais. Merece destaque o fato de que, nas criações da região estudada, a higienização das instalações não é feita com frequência (Alencar et al., 2010), levando ao acúmulo de esterco, que é considerado um substrato ideal para reprodução de certas espécies de Culicoides (Alves et al., 2009).

A partir das condições parcialmente favoráveis à manutenção do vetor no semiárido, o vírus seria mantido por meio do ciclo clássico ruminanteinseto-ruminante, destacadamente nas espécies que apresentam viremia mais prolongada e em alto título, como bovinos (MacLachlan et al., 1991) e caprinos ((Koumbati et al., 1999). É necessário acrescentar, ainda, a existência de ruminantes silvestres - veado caatingueiro (Mazama gouazoupira, veado mateiro ( $M$. americana) - como habitantes naturais do bioma Caatinga presentes no semiárido (Oliveira et al., 2003), que poderiam participar na manutenção do vírus.

Durante os trabalhos de campo, não foram constatados casos clínicos de LA, embora haja registro de sinais clínicos que poderiam ter alguma relação com casos brandos dessa doença, como os descritos por Alencar et al. (2010) na região do sertão de Pernambuco, envolvendo 147 criações de caprinos e ovinos.

No estudo desses autores, ocorreram abortamento, $82,3 \%$ das criações, lesões nos lábios, 66\%, catarro nasal, 63,3\%, defeitos congênitos, $60,5 \%$, tosse, $59,2 \%$ e lesões nos cascos, $43,2 \%$. Em outros estudos no semiárido nordestino, também têm sido relatados abortamento (75\%), malformações congênitas $(15 \%)$ e pododermatite $(67 \%)$. É provável que a baixa incidência de casos clínicos e o desconhecimento dos diferentes sintomas causados pelo VLA e sua diferenciação com outros problemas sanitários tenham dificultado a identificação de surtos de LA pelos criadores e veterinários.

Pelo exposto e considerando-se a importância tanto social quanto econômica das pecuárias caprina e ovina para o semiárido, é essencial, como medida preventiva, o controle de importações de ruminantes para essas áreas.

Palavras-chave: arbovirose, Culicoides, epidemiologia 


\begin{abstract}
The prevalence of antibodies against bluetongue virus was investigated in 41 dairy goats and 40 sheep herds in the semi-arid region of Pernambuco state and the conditions for insect Culicoides maintenance, considering climate dynamics and vector competence, were evaluated. The percents of seropositive herds in agar gel immunodiffusion test for bluetongue virus group were 24 for goats and 27.5 for sheep. The estimated prevalences of seropositive animals were $3.9 \%$ for goats $(n=410)$ and $4.3 \%$ for sheep $(n=$ 400). The prevalences of seropositive animals were low in the mesoregion of Sertão Pernambucano (4.8\% for goats and $4.1 \%$ for sheep) and São Francisco Pernambucano (1.0\% for goats and $4.5 \%$ for sheep). There were no significant differences between species and regions. Considering the social and economic importance of goats and sheep raising in the semi-arid region, it is essential to establish preventive measures to control imports of ruminants from these areas.
\end{abstract}

Keywords: arbovirosis, Culicoides, epidemiology

\section{AGRADECIMENTOS}

Ao Conselho Nacional de Desenvolvimento Científico e Tecnológico (CNPq), à Fundação de Amparo à Ciência e Tecnologia do Estado de Pernambuco (FACEPE), à Financiadora de Estudos e Projetos (FINEP).

\section{REFERÊNCIAS BIBLIOGRÁFICAS}

ALENCAR, S.P.; MOTA, R.A.; COELHO, M.C.O.C. et al. Perfil sanitário dos rebanhos caprinos e ovinos no sertão pernambucano. Cienc. Anim. Bras., v.11, p.131-140, 2010.

ALVES, F.A.L.; ALVES, C.J.; AZEVEDO, S.S. et al. Soroprevalência e fatores de risco para a língua azul em carneiros das mesorregiões do Sertão e da Borborema, semiárido do estado da Paraíba. Cienc. Rural, v.32, p.484-489, 2009.

COSTA, J.R.R.; LOBATO, Z.I.P.; HERRMANN, G.P. et al. Prevalência de anticorpos contra o vírus da língua azul em bovinos e ovinos do sudoeste e sudeste do Rio Grande do Sul. Arq. Bras. Med. Vet. Zootec., v.58, p.273-275, 2006.

DEAN, A.G.; DEAN, J.A.; BURTON, A.H. Epi Info 6: version 1.2 a word processing, date base, and statistic program for epidemiology on microcomputaters. Atlanta: Center for Disease Control, 2001.

FORATTINI, O.P. Culicoides da região neotropical (Diptera Ceratopogonidae). Arq. Fac. Hig. Saúde Pública, v.11, p.159-526, 1957.

KOUMBATI, M.; MANGANA, O.; NOMIKOU, K. et al. Duration of bluetongue viraemia and serological responses in experimentally infected European breeds of sheep and goats. Vet. Microbiol., v.64, p.277-285, 1999.
LAENDER, J.O. Língua azul em rebanhos de ovinos e capirnos em três mesorregiões de Minas Gerais: análise de evidência e sorológica e identificação de Culicoides sp. 2002. 92f. Dissertação (Mestrado) Escola de Veterinária, Universidade Federal de Minas Gerais, Belo Horizonte, MG.

MacLACHLAN, N.J.; CONLEY, A.J.; KENNEDY, P.C. Bluetongue and equine viral arteritis viruses as models of virus-induced fetal injury and abortion. Anim. Reprod. Sci., v.60/61, p.643-651, 1991.

MELO, C.B.; OLIVEIRA, A.M.; AZEVEDO, E.O. et al. Anticorpos contra o vírus da língua azul em bovinos do sertão da Paraíba. Arq. Bras. Med. Vet. Zootec., v.52, p.19-20, 2000.

MELLOR P.S.; BOORMAN J.; BAYLIS M. Culicoides biting midges: their role as arbovirus vectors. Ann. Rev. Entomol., v.45, p.307-340, 2000.

OLIVEIRA, J.A.; GONÇALVEZ, P.R.; BONVICINO, C.R. Mamíferos da caatinga. In: LEAL, I.R.; TABARLLI, M.; SILVA, J.M.C. Ecologia $e$ conservação da caatinga. Recife: Editora Universitária, 2003. 275-302.

SILVA, M.X. Prevalência do vírus da língua azul pelo teste de imunodifusão em gel de Ágar (IDGA) $e$ determinação de níveis tecnológicos de propriedades com rebanhos caprinos no estado do Ceará, Brasil. 2002. 68f. Dissertação (Mestrado) - Escola de Veterinária, Universidade Federal de Minas Gerais, Belo Horizonte, MG.

TOMICH, R.G.P.; NOGUEIRA, M.F.; LACERDA, A.C.R. et al. Sorologia para o vírus da língua azul em bovinos de corte, ovinos e veados campeiros no Pantanal sul-mato-grossense. Arq. Bras. Med. Vet. Zootec., v.61, p.1222-1226, 2009.

WALKER A.R.; DAVIES F.G.A preliminary survey of the epidemiology of bluetongue in Kenia, J. Hyg. Cambrid., v.69, p.47-60, 1971. 